\title{
APROXIMACIÓN AL VOTO ELECTRÓNICO PRESENCIAL: ESTADO DE LA CUESTIÓN Y RECOMENDACIONES PARA SU IMPLANTACIÓN
}

\author{
LUIS A. GÁLVEZ MUÑOZ \\ Profesor Titular de Derecho Constitucional \\ Universidad de Murcia
}

SUMARIO

I. El voto electrónico en perspectiva.

II. El voto en papel como base del régimen actual de votación.

III. La alternativa del voto electrónico presencial y los problemas del voto electronico a distancia.

IV. Normativa y ensayos sobre el voto electrónico. La doctrina de la Junta Electoral Central.

V. Recomendaciones básicas sobre su implantación.

El avance que ha experimentado el voto electrónico en los últimos años en todo el mundo, los efectos de todo tipo que su introducción puede tener sobre el ejercicio del derecho de sufragio y el desarrollo del proceso electoral en su conjunto, los ensayos que del mismo se vienen realizando en España desde hace varios años y el progresivo e irrefrenable proceso de tecnificación que la sociedad española está experimentado en sus más diversos ámbitos, son la base sobre la que se articula este trabajo. En él se estudia el estado actual de la legislación relativa a los instrumentos materiales de votación, la oportunidad de la implantación del voto electrónico presencial y sus alternativas, la normativa actualmente existente en España sobre esta forma de votación, la doctrina de la Junta Electoral Central sobre los ensayos que se proponen y, finalmente, la mejor forma de proceder a su implantación. Se trata, en definitiva, de poner de relieve el estado de la cuestión y sentar algunas recomendaciones en la materia. 


\section{EL VOTO ELECTRONICO EN PERSPECTIVA ${ }^{1}$}

El voto electrónico "está de moda". Las posibilidades de su implantación, las ventajas que supone, los riesgos que entraña o los costes que conlleva se encuentran en boca de muchos. El plantel de participantes es muy variado, pues comprende a periodistas, políticos, especialistas en comunicación pública, Ciencia Política y Derecho Constitucional y, en general, a todos los ciudadanos interesados por la marcha de los asuntos públicos.

Es ésta, sin embargo, una moda en la que, a poco que se escarbe, es posible descubrir aromas añejos. Como ocurre con tantos otros temas de la vida, el enorme y creciente interés que suscita hoy día el voto electrónico, puede producir en muchos muchos una especie de déjà vu o paramnesia, es decir, la extraña sensación de que ya se ha vivido o experimentado determinada situación o fenómeno que ahora aparece ${ }^{2}$. En este sentido, es conveniente recordar que durante los años cincuenta del pasado siglo, con ocasión del despegue tecnológico y de la vitalidad democrática que siguieron a la conclusión de la Segunda Guerra Mundial, el voto electrónico tuvo un momento dulce, especialmente a partir de la entrada en escena de la Comisión Electoral Federal de los Estados Unidos. Basta pensar que, en una fecha tan temprana como 1957, W. J. M. Mackenzie pudo decir que este sistema de votación se había hecho "casi universal en los Estados Unidos por adaptarse perfectamente al régimen americano, que determina (aun en votaciones de candidatura reducida) la participación del elector en varias elecciones a la vez" y que "Ofrece grandes ventajas" ${ }^{3}$.

Hoy, de todas formas, la situación es muy diferente a entonces. En los más de cincuenta años transcurridos se han producido importantes cambios. Ha avanzado en primer lugar, desde luego, la técnica, que pone a nuestra disposición instrumentos muy útiles y de fácil manejo (pantallas táctiles, urnas con lector automático de votos, etc.); ha habido también numerosos estudios y experiencias, que han cristalizado en normas, protocolos y recomendaciones de muy diverso tipo; y se ha consolidado y extendido el movimiento legislativo en pro del voto electrónico, pues son ya muchos los países que, en mayor o menor grado, lo han adoptado o se encuentras en vías de hacerlo.

España, como es sabido, no se encuentra en este grupo de vanguardia. Está en una fase que podría calificarse como de aavanzada". Decimos esto porque, aunque nuestro país no ha incorporado a su ordenamiento esta forma de

1 Este trabajo se enmarca dentro del proyecto de investigación sobre «Revisión y mejora del Derecho Electoral" (Código SEJ 2005-09295/JURI), subvencionado por el Ministerio de Educación y Ciencia y por los Fondos FEDER de la Unión Europea.

2 Este término fue acuñado por el investigador psíquico francés Émile BoIrac (1851-1917) en su libro L'Avenir des sciences psychiques (El futuro de las ciencias psíquicas), basado en un ensayo que escribió mientras estudiaba en la Universidad de Chicago.

3 Vid. W. J. M. Mackencie, Elecciones libres, traducción española de F. Condomines Pereña, Tecnos, Madrid, 1962, pág. 150 (edición original: Free elections, 1957). Añade el autor que "los europeos consideran esta mecanización algo típicamente americano y un poco absurdo". 
instrumentar el ejercicio del sufragio, ya ha dado varios pasos en orden a su acogida; se encuentra, en concreto, en un estadio adelantado de la fase de estudios y ensayos. Así, existe desde hace varios años una comisión técnica en el Ministerio del Interior encargada de evaluar la implantación del voto electrónico y son ya muchos los ensayos de este orden realizados en nuestro país, el más relevante de los cuales, por distintas razones, tuvo lugar con ocasión del referéndum sobre la Constitución europea en febrero de 2005.

Por otra parte, el voto electrónico es, hoy día, uno de los objetos posibles de la reforma electoral que se avecina, como pone de relieve el hecho de que se le cite expresamente en el texto de la petición de informe que el Gobierno de la Nación cursó, a mitad de 2008, al Consejo de Estado en orden a la modificación del régimen electoral general ${ }^{4}$. Tiene, por lo demás, un espléndido futuro en orden a articular el voto de los españoles en el exterior, dada las dificultades que plantea tanto el voto por correo $^{5}$, como el voto tradicional en urna.

La actualidad de este tema y su importancia intrínseca en orden al más eficaz y adecuado ejercicio del derecho fundamental del sufragio es, precisamente, lo que nos ha llevado a indagar sobre el mismo. Nos preguntamos sobre el estado actual de la legislación relativa a los instrumentos materiales de votación, la oportunidad de la implantación del voto electrónico en España, así como sobre la mejor forma de hacerlo. Se trata, por tanto, de poner de relieve el estado de la cuestión y sentar algunas recomendaciones en la materia.

\section{EL VOTO EN PAPEL COMO BASE DEL RÉGIMEN ACTUAL DE VOTACIÓN}

La determinación de los instrumentos materiales de votación, es decir, de todos aquellos medios que ha de utilizar el elector a la hora de elaborar y expresar su opción política, es una de las decisiones más relevantes que ha de tomar el legislador a la hora de regular la organización de las elecciones. Y no

4 En los inicios de la IX Legislatura se ha puesto en marcha un ambicioso proceso de reforma de la legislación electoral, tanto por parte del Gobierno como del Parlamento. Así, el Gobierno acordó el 27 de junio de 2008 solicitar del Consejo de Estado, en virtud de lo dispuesto en el artículo 2.3 de la Ley Orgánica de 22 de abril de 1980, un Informe sobre las determinaciones constitucionales del régimen electoral general y sobre las principales propuestas de reforma del mismo que han sido objeto de debate político y doctrinal, analizando en particular tanto su ajuste al marco constitucional como su funcionalidad para el conjunto del sistema. El Congreso de los Diputados creó, por su parte, con fecha de 10 de septiembre de 2008, una Subcomisión, dentro de la Comisión Constitucional, para el estudio de las posibles modificaciones del régimen electoral genera (Vid. Diario de Sesiones del Congreso de los Diputados, IX Legislatura, Pleno, núm. 24, de 10 de septiembre de 2008, pág. 51. Para el debate vid. Diario de Sesiones del Congreso de los Diputados, IX Legislatura, Comisiones, núm. 68, de 5 de septiembre de 2008, págs. 2 y ss.).

5 Sobre el fracaso de este sistema de votación en relación con los emigrantes vid. Gálvez MuÑoz, L A., "El voto por correo: ¿una nueva reforma?, Revista de Derecho Politico, núm. 52, 2001, págs. 249 y ss. (número monográfico sobre "el sistema electoral"). 
decimos esto por la trascendencia política que esta cuestión pueda tener —que no es, ciertamente, acusada, aunque alguna sí tiene-, sino por la incidencia que pueda ocasionar en la regularidad del proceso electoral y, por tanto en su misma credibilidad.

Los medios o instrumentos materiales de votación que nuestro actual ordenamiento jurídico — Ley Orgánica 5/1985, de 19 de junio, del Régimen Electoral General (en adelante LOREG) y Real Decreto 605/1999, de 16 de abril, de regulación complementaria de los procesos electorales - prevé en orden a hacer posible el ejercicio del derecho de sufragio son cuatro. A saber:

- Papeletas en las que los electores puedan expresar su opción política.

- Sobres para que los electores pueden introducir en ellos las papeletas de su elección, sin que su contenido quede al descubierto.

- Urnas en donde depositar los sufragios.

- Y cabinas que permitan a los electores elegir su opción política fuera de la vista de las demás personas que se hallen en el local electoral.

Estos instrumentos tienen cierta tradición en nuestro Derecho, pues son los mismos que los que establecía la legislación electoral de la transición ${ }^{6}$. No obstante, los antecedentes normativos análogos acaban aquí, habida cuenta que las normas electorales anteriores no contemplaban ni la existencia de cabinas de votación, ni la utilización de sobres electorales.

Desde el Real Decreto de 24 de mayo de 1836 para la elección de Procuradores a las Cortes Generales del Reino hasta poco antes de la restauración democrática producida tras el acceso de don Juan Carlos I a la Jefatura del Estado, el procedimiento de votación ha pivotado sobre dos únicos instrumentos: papeletas y urnas. El elector tenía que rellenar o, en su caso, seleccionar una papeleta de votación, doblarla y entregársela al Presidente de la Mesa Electoral, quien la debía introducir inmediatamente en la urna.

El sistema actual, con cabinas y sobres de votación, además de papeletas y urnas electorales, es, sin duda, mucho mejor, pues garantiza de forma más completa y adecuada la libertad y el secreto del voto. Piénsese que en algunos momentos históricos la falta de cabinas y sobres ha ido acompañada de la previsión normativa de la entrega de la papeleta electoral, en blanco, por el Presidente de la Mesa al elector, quien, "dentro del local y a la vista de la Mesa", debía proceder a escribir el nombre del candidato o candidatos elegidos y, acto seguido, devolvérsela al Presidente para su introducción en la urna?

6 Vid. los artículos 54 y 55 del Real Decreto Ley 20/1977, de 18 de marzo, sobre normas electorales; el Real Decreto 876/1977, de 15 de abril, por el que se regulan los modelos oficiales a que se ajustarán las urnas, cabinas, papeletas electorales, sobres y documentos en las elecciones al Congreso de los Diputados y al Senado; y el Real Decreto 3075/1978, de 29 de diciembre, por el que se establecen los modelos de urnas, cabinas, papeletas, sobres y documentos para las elecciones y cómputo de plazos.

7 Así lo exigía la Ley Electoral de 18 de marzo de 1846 para el nombramiento de Diputados a Cortes. Su artículo 47 decía así: «La votación será secreta. El Presidente entregará una papeleta 
La base fundamental de la ventaja que presenta la regulación actual está, indudablemente, en la introducción de la cabina de votación, pues su uso permite al elector seleccionar o rellenar su papeleta electoral fuera de la vista de las demás personas presentes en el local. La utilización del sobre de votación nos parece, por el contrario, de mucha menor importancia y, por tanto, susceptible de eliminación por el legislador (aunque no la propugnemos), siempre que se cumplieran determinadas condiciones: que haya instrucciones precisas sobre la forma de doblar la papeleta, que la papeleta resulte totalmente opaca y que, lógicamente, exista siempre la posibilidad de seleccionar y doblar la papeleta electoral de forma reservada.

Los instrumentos materiales de confección del voto previstos en la actual legislación electoral española son también, por otra parte, los que existen en la mayoría de los ordenamientos jurídicos extranjeros y, particularmente, en los de nuestro entorno más próximo. No obstante, hay países que escapan, en mayor o menor grado, a este esquema básico. A este respecto conviene realizar dos puntualizaciones:

- En primer lugar, que hay algunos países, como Italia, en donde no se utilizan sobres de votación para expresar el sufragio, sino directamente papeletas electorales, de tal modo que las papeletas, una vez seleccionadas o rellenadas por los electores, se doblan y se introducen directamente en la urna ${ }^{8}$. Los demás materiales de votación no varían.

- Y, en segundo término, que hay otros países (Estados Unidos, Bélgica, Países Bajos, Alemania9 ${ }^{9}$, Paraguay, Brasil, Venezuela, India, Filipinas) que han implantado, de forma más o menos amplia, el llamado «voto electrónico" en los colegios electorales, lo cual supone una notable alteración de los instrumentos materiales de votación, pues, en los casos más extremos, implica la desaparición de sobres, papeletas e incluso de las urnas de votación y su sustitución por una máquina u ordenador capaz de realizar de forma automática el registro y cómputo de los votos emitidos ${ }^{10}$.

rubricada al elector. Éste escribirá en ella dentro del local y a la vista de la Mesa, o hará escribir por otro elector, el nombre del candidato a quien dé su voto, y devolverá la papeleta doblada al Presidente. El Presidente depositará la papeleta doblada en la urna a presencia del mismo elector, cuyo nombre y domicilio se anotarán en una lista numerada". Vid. también, aunque sin la referencia expresa al rellenado de la papeleta dentro del local, el artículo 20 del Real Decreto de 24 de mayo de 1836 para la elección de Procuradores a las Cortes Generales del Reino y el artículo 25 de la Ley Electoral de 20 de julio de 1837.

8 Vid. los artículos 31 y 58 del Decreto del Presidente de la República de 30 de marzo de 1957, núm. 361, por el que se aprueba el texto único de las leyes sobres elecciones a la Cámara de Diputados.

9 Alemania es el país europeo que con mayor prontitud adoptó el voto electrónico, aunque su aplicación es minoritaria, pues solo alcanza al 5\% de los electores. Vid. el artículo 35 de la Ley Federal de Régimen Electoral, que contempla la emisión del sufragio mediante "aparatos de voto" y que ha sido desarrollado por el Decreto de 3 de septiembre de 1975 sobre la utilización de aparatos para votar en las elecciones a la Dieta Federal Alemana.

10 Existen otros muchos países en donde está en estudio la implantación del voto electrónico, en alguno de los cuales se han llevado a cabo ensayos de aplicación sobre grupos más o 


\section{LA ALTERNATIVA DEL VOTO ELECTRÓNICO PRESENCIAL Y LOS PROBLEMAS DEL VOTO ELECTRONICO POR INTERNET}

Esta segunda puntualización que hemos realizado en relación con el Derecho Comparado tiene un indudable interés, pues nos pone de relieve el futuro, más o menos próximo, que tiene la regulación de los instrumentos materiales de votación en España. Y es ello precisamente lo que justifica, como ya adelantamos, el estudio de esta materia ${ }^{11}$.

No se trata de lanzar una profecía sin fundamento, sino de constatar una realidad al acecho. El cambio parece inevitable. El voto electrónico, por un lado, se adecua perfectamente al progresivo e irrefrenable proceso de tecnificación de la sociedad en sus más diversos ámbitos, incluso en los más cotidianos y próximos al ciudadano (pagar la compra, sacar dinero del banco, acceder al sistema sanitario...); y, por otro lado, presenta indudables ventajas respecto al voto tradicional, como facilitar el recuento de los sufragios, reducir los gastos electorales o eliminar los conflictos sobre validez de determinadas papeletas.

La implantación del voto electrónico en los colegios electorales, en tanto procedimiento ordinario de votación es, pues, cuestión de tiempo. Lo que no podemos saber, sin embargo, es cómo y cuándo se producirá el cambio, pues las modalidades y ritmos de introducción de esta forma de votación son muy variados ${ }^{12}$. Por citar tres casos: cabe introducir el voto electrónico únicamente de modo opcional; puede, en segundo lugar, introducirse el voto electrónico de forma complementaria al voto tradicional, por medio de la emisión por la máquina de votación de un resguardo en papel que se introduce

menos amplios de población, como Francia, Italia, Portugal, Inglaterra o nuestro propio país. En relación con el Derecho comparado vid., en general, el documento de trabajo del Senado francés sobre el voto electrónico, correspondiente a la serie "legislación comparada" (n. ${ }^{\circ}$ LC 176, de septiembre de 2007, accesible en su página web: http://www.senat.fr), si bien está centrado en Europa; el estudio realizado por el Departamento de Interior del Gobierno vasco sobre el voto electrónico en otros países (accesible en http://www.euskadi.net/elecciones); y José J. FERnÁndez RODRíguez y otros, Voto electrónico: estudio comparado en una aproximación jurídico-política, FUNDAP (Fundación Universitaria de Derecho, Administración y Política), Santiago de Querétaro (México), 2007.

11 El voto electrónico, entendiendo esta expresión en sentido amplio, es objeto de un creciente interés doctrinal, en conexión con el tema más general del gobierno o la democracia electrónicos. Limitándonos a España y a las obras más recientes cabe destacar H. CAIro Carou, Democracia digital. Limites y oportunidades, Madrid, Trotta, 2002; Lorenzo Cotino Hueso (coord.), Libertades, democracia y gobierno electrónicos, Comares, Granada, 2006; Lorenzo cotino huEso (coord.), Democracia, participación y voto a través de las nuevas tecnologías, Comares, Granada. 2007; y José J. Fernández Rodríguez, "El voto electrónico en la balanza”, en Revista Parlamentaria de la Asamblea de Madrid, núm. 17, diciembre 2007, págs. 205 y ss.

12 Hay que tener mucho cuidado en la forma y ritmo de implantación del voto electrónico, pues en algunos países los problemas que a veces genera su práctica ha provocado reacciones contra el método en su conjunto. Es el caso, por ejemplo, de California, cuyo Senado prohibió en mayo de 2004 el uso de máquinas electrónicas de votación; o de Irlanda, donde el Gobierno suspendió en 2003 el proyecto de implantación del voto electrónico, de acuerdo con el informe negativo emitido por la Comisión sobre el voto electrónico. 
en una urna tradicional; y cabe, finalmente, basar la votación únicamente en su emisión electrónica.

La única alternativa que cabe pensar frente a esta previsible próxima realidad es la del voto por internet ${ }^{13}$. Se trata de la posibilidad de que el legislador opte en un futuro próximo por el voto por internet desde cualquier lugar, lo cual no es en absoluto impensable, habida cuenta la notable extensión que está alcanzando este medio de comunicación entre la población. No cabe duda de que nos encontramos ante un medio cada vez más conocido y usado, con cotas de crecimiento muy elevadas y que en unos pocos decenios se puede llegar en España a la universalización del mismo.

En este sentido, hay que reconocer que la posible utilización de internet como instrumento de votación tiene, en principio, un elemento muy relevante a su favor: el de facilitar el ejercicio del derecho de sufragio, pues permite al elector votar cómodamente desde casa o el trabajo; y no es tampoco aventurado pensar que cuanto más cómodo sea el hecho de votar, más gente votará ${ }^{14}$. El argumento es, sin embargo, poco consistente, pues si bien es cierto que a muchas personas el uso de internet le puede facilitar la emisión del voto, también es verdad que a otras muchas, poco familiarizadas con las nuevas tecnologías, les puede suceder lo contrario, es decir, que le complique enormemente el acto de votación, sin que haya ninguna autoridad electoral al lado suyo que le pueda auxiliar.

En cualquier caso, no hay que olvidar sus limitaciones. La principal es que el voto por internet plantea graves problemas para la integridad de la mayoría de los principios del sufragio. Así, es difícil garantizar que el voto lo emite realmente el elector y no otra persona por él; que lo hace en un ambiente de plena libertad, sin coacción de ningún tipo; y que el sentido de su voto va a permanecer en secreto, sin poder ser espiado o desvelado por nadie.

Hay que tener en cuenta, además, otros problemas. Entre otros, cabe citar la pérdida del control de la votación por parte de los electores (miembros de Mesas Electorales) y los militantes de los partidos (interventores) en beneficio de los profesionales de la informática; el menoscabo del rito de las elecciones, que tanta importancia tiene como factor de integración de la comunidad; y las dudas sobre la seguridad de las comunicaciones electrónicas.

Todos estos problemas hacen que el voto por internet, como sustituto del voto directo en las Mesas electorales por medio de papeletas y sobres de votación, no nos parezca lo más adecuado. Del voto por internet podríamos de-

13 En relación con la democracia electrónica y los sistemas de votación a través de la red vid. el interesante artículo de Juan A. Martínez CaSTAÑo, "Voto electrónico y software libre", en http://oasis.dit.upm.es/ jantonio, agosto 2000.

14 Sobre este punto vid. la intervención de Kim AlEXANDER, en el "coloquio" recogido en Francesc PAU I VALL (coordinador), El Parlamento del siglo XXI. VIII Jornadas de la Asociación Española de Letrados de Parlamentos, Tecnos y Aelpa, Madrid, 2002, pág. 103. La relación entre voto electrónico y aumento de la participación no está, sin embargo, nada clara; vid. al respecto Josep M. ${ }^{a}$ Reniu Vilamala, "Ocho dudas razonables sobre el voto electrónico", en Revista de Internet, Derecho y Política, núm. 6, 2008, pág. 39. 
cir lo mismo que hace años expresó un insigne especialista en cyberdemocracia, Kim AlexAnDer:

"Yo empecé como mucha gente siendo entusiasta de la idea de votar a través de internet, mientras que ahora, cuanto más aprendo sobre el tema más cuenta me doy de que no es una buena idea ${ }^{15}$.

Esto no significa, sin embargo, que internet no pueda tener ninguna aplicación en el proceso de votación. En modo alguno:

- En primer lugar, internet podría ser en el futuro, a nuestro juicio, un instrumento válido de votación, sustituto del correo, en relación con todos aquellos electores que, por el motivo que sea, no pueden personarse en su colegio electoral el día de las elecciones, pero siempre, naturalmente, que se establezcan las medidas que sean precisas para eliminar o reducir sensiblemente sus limitaciones.

- Y, en segundo término, internet puede servir, sobre todo, como canal de comunicación por medio del cual poder realizar trámites electorales que, hoy por hoy, hay que hacer en persona o por correo.

Pensamos, por tanto, de acuerdo con todo lo dicho, que las opciones futuras están en el voto electrónico en las Mesas electorales. Esta forma de votación combina de modo muy adecuado los adelantos de la técnica con las enormes ventajas que presenta el voto directo o por personación del elector en relación con el voto a distancia.

\section{NORMATIVA Y ENSAYOS SOBRE EL VOTO ELECTRÓNICO. LA DOCTRINA DE LA JUNTA ELECTORAL CENTRAL}

El voto electrónico carece en la actualidad, como es sabido, de regulación en España. Tan solo contamos con una excepción en el ámbito electoral autonómico: se trata de la Ley de Elecciones al Parlamento Vasco, que dedica un capítulo a regular un procedimiento de votación electrónica presencial, basado en la sustitución de las papeletas y sobres de votación por una tarjeta con banda magnética en la que el elector ha de introducir su decisión electoral a través de un ordenador ${ }^{16}$. 103.

15 Vid. Kim Alexander, en Francesc Pau i Vall (coordinador), El Parlamento..., op. cit., pág.

16 Vid. el Capítulo X (Procedimiento de la votación electrónica) del Título V (Procedimiento electoral) de la Ley 5/1990, de 15 de junio, de Elecciones al Parlamento Vasco, según la redacción dada por la Ley 15/1998, de 19 de junio. Comprende los artículos 132 Bis a 132 Septies. Los elementos del sistema de voto electrónico previstos en esta Ley son los siguientes: la tarjeta con banda magnética de votación, la urna electrónica, la pantalla de votar, la cabina electoral y el software o programa informático electoral. 
Es ésta, sin embargo, una excepción muy relativa o sui generis, pues, hasta el momento, esta normativa específica no ha tenido aplicación alguna, hallándose, además, hoy día, inmersa en un proceso de evaluación y revisión por parte del Parlamento Vasco ${ }^{17}$. A este respecto conviene tener presente algunos datos:

- El Consejo del Gobierno Vasco aprobó el 15 de junio de 2004 un Proyecto de Ley de Reforma de la Ley de Elecciones al Parlamento Vasco de 1990 en relación con el voto electrónico ${ }^{18}$.

- Los grupos parlamentarios presentaron un total de 16 enmiendas, tres de ellas a la totalidad, pero que no pudieron debatirse como consecuencia de la disolución del Parlamento con motivo de la convocatoria de elecciones autonómicas del 17 de abril de 2005.

- En la siguiente legislatura, la octava y actual, el Departamento de Interior del Gobierno Vasco se comprometió formalmente a abrir un espacio de reflexión compartido con los grupos parlamentarios sobre la oportunidad y orientación del referido Proyecto de Ley de voto electrónico y sobre el desarrollo general de la actual Disposición final primera de la vigente Ley 15/1998, de modificación de la Ley de Elecciones al Parlamento Vasco, relativa a la aplicación del voto electrónico en los procesos electorales.

- Ese diálogo ha comenzado de forma tímida y todavía no ha dado ningún resultado.

Por lo demás, lo único que han hecho los poderes públicos es realizar varios ensayos de votación electrónica en algunas localidades y Mesas Electorales concretas. Estos ensayos están teniendo lugar en todo el país desde hace casi dos décadas, a iniciativa de diversas Administraciones y en relación con elecciones y referendos de todo tipo, aunque en los últimos tiempos cabe destacar el papel activo que están teniendo algunas Comunidades Autónomas en relación con sus elecciones parlamentarias, como es el caso de Cataluña ${ }^{19}$.

17 El sistema previsto en la Ley está en discusión como respuesta a las objeciones, preocupaciones y sugerencias de los partidos políticos con representación en el Parlamento Vasco, los cuales requerían un nuevo sistema que integrara en uno solo los dos procedimientos de voto tradicional y de voto electrónico. En este proceso de reflexión se ha constatado que el principal reto en los sistemas de votación electrónica es la proximidad al ciudadano, evitando que se dé una situación de ajenidad.

18 Sobre este proyecto vid. Rosa M. ${ }^{a}$ Fernández RIVEIRA, «El incierto potencial derivado de la conjunción derecho de voto y nuevas tecnologías. El nuevo proyecto de ley de voto electrónico en Euskadi”, en Nuevas Politicas Públicas: Anuario multidisciplinar para la modernización de las Administraciones Públicas, núm. 1, 2005 (ejemplar dedicado a Los derechos fundamentales y las nuevas tecnologías), págs. 345-369.

19 Sobre los diversos ensayos efectuados en nuestro país vid. Enrique ARNALDo Alcubilla y Aldo D'Ambrosio I GomárIz, "El voto electrónico: algunas experiencias recientes", Cuadernos de Derecho Público, núm. 4, 1998, págs. 159 y ss.; Rosa M. ${ }^{a}$ Fernández RIveIRA, «El voto electrónico: el caso vasco", Revista de Estudios Politicos, núm. 112, 2001; Josep M. ${ }^{a}$ Reniu Vilamala, Democracia electrónica y participación ciudadana: informe sociológico y jurídico de la consulta ciu- 
La puesta en práctica de estas iniciativas ha contado en todos los casos con el parecer favorable de la Junta Electoral Central. Este órgano no ha tenido inconveniente en "autorizar" o "informar favorablemente" la realización de ensayos de votación electrónica, siempre y cuando los mismos cumplieran ciertas condiciones. De ellas cabe destacar las siguientes:

- Que la utilización del voto electrónico es una facultad de la que el elector puede hacer uso voluntariamente.

- Que ha de respetarse en todo caso el secreto del voto.

- Que la votación electrónica no debe interferir ni el desarrollo de la votación ni durante el escrutinio.

- Y que los ensayos no tienen otro carácter que el de prueba para estudiar su hipotética implantación en el futuro, sin eficacia jurídica alguna ${ }^{20}$.

Son muchas las resoluciones de la Junta Electoral Central en que se plasma esta doctrina y que, por tanto, son susceptibles de traer aquí. No obstante, valga por todas la resolución de la Junta Electoral Central de 7 de mayo de 2003, emitida como consecuencia de la consulta de la Generalitat de Cataluña en relación con las elecciones autonómicas de 2003:

"Comunicar que, en cuanto la utilización del voto electrónico es una facultad de la que el elector puede hacer uso voluntariamente, siempre a continuación de depositar la papeleta, y salvándose en todo caso el secreto de sufragio, teniendo en cuenta que no tiene otro carácter que el de prueba para estudiar su hipotética implantación en el futuro, y siempre que no interfiera ni el desarrollo de la votación ni el escrutinio, en los términos establecidos en la L.O.R.E.G., no hay ninguna objeción a plantear por esta Junta Electoral Central. La única votación y el único escrutinio válidos a todos los efectos serán los efectuados ante y por, respectivamente, la Mesa electoral ${ }^{21}$.

dadana; Ayuntamiento de Madrid, Madrid, 2004; Carmen RAMILO ARAUjO, "Gobierno electrónico en la práctica: experiencias de interés en la CAPV", Revista Vasca de Administración Pública, núm. 67, 2003, págs. 329 y ss.; Jordi Barrat i Esteve y Josep Ma Reniu I Vilamala, Prueba piloto en Cataluña (España). Informe sobre las elecciones catalanas de noviembre de 2003, en http://www.votobit.org; y Manuel Delgado-IRIBARREN GARCíA-CAMPERO, "Voto electrónico y garantías electorales: las recientes experiencias de Brasil y España", Revista de las Cortes Generales, núm. 63, 2004, págs. 175 y ss.

20 Vid. los Acuerdos de la Junta Electoral Central de 25 de octubre de 1995, 24 de mayo de 1999, 7 de mayo de 2003, 10 de julio de 2003, 29 de enero de 2004, 25 de enero de 2005 y 2 de junio de 2005 (este último se complementa con los de 20 y 26 de mayo de 2005). En algunos casos la Junta ha rechazado solicitudes de ensayo por falta de garantías (Acuerdos de 9 de febrero de 2000, 16 de diciembre de 2002, 26 de marzo de 2003, 22 de marzo de 2007 y 17 de enero de 2008). En relación con estos Acuerdos vid. los archivos de la Junta Electoral Central y Enrique ARnaldo Alcubilla y Manuel Delgado-Iribarren Garcia-Campero, Código electoral, 6. ${ }^{\text {a }}$ edición, Abella, Madrid, 2008, págs. 498-500.

21 En este Acuerdo de 7 de mayo de 2003 la Junta Electoral Central añadía: "Por otro lado, se interesa que por la Consejería de Presidencia del Gobierno Autonómico se informe a la Junta Electoral Central de los pasos dados — incluyendo la carta a remitir a los electores, en la que se harán constar los extremos referidos en este acuerdo- y del resultado final de la prueba". 
La condición más discutible establecida por el máximo órgano de nuestra Administración electoral es la última de las mencionadas, es decir, la que define la naturaleza de mera prueba, sin validez jurídica, de los ensayos de voto electrónico. La Junta Electoral se ha mostrado, sin embargo, inflexible, ante su exigencia con el argumento fundamental de que la insuficiencia normativa no le permite adoptar otra decisión. Así lo dice en un Acuerdo reciente, relativo a las elecciones autonómicas madrileñas de mayo de 2007:

«Esta Junta, en relación a la propuesta remitida a por el Secretario General del Consejo de Gobierno de la Comunidad de Madrid, tiene a bien informar lo siguiente: Que esta Junta siempre ha sido receptiva y se ha mostrado favorable a la incorporación de nuevos medios tecnológicos siempre que se lleve a cabo por los cauces que el ordenamiento jurídico prevé y con pleno respeto de las garantías electorales. Que conforme a lo dispuesto en el artículo 81.3 de la LOREG - aplicable con carácter supletorio de acuerdo con lo previsto en el Apartado 3 de la Disposición Adicional Segunda de la LOREG, al no existir previsión legal en la Ley de la Comunidad de Madrid $11 / 1986$, de 16 de diciembre- las urnas y las papeletas deben ajustarse al modelo oficialmente establecido, que en este momento es el que recoge el Real Decreto 605/1999, de 16 de abril, por el que se establece la regulación complementaria de los procesos electorales, en sus artículos 2 y 4 , así como en los Anexos 1 y 3. Que la cercanía a la convocatoria del proceso electoral, la inexistencia de acreditación del correcto funcionamiento del sistema propuesto, la confusión que podría provocar en los electores la concurrencia en la misma Mesa de urnas manifiestamente diferentes, son factores que unidos a la ausencia de un marco normativo suficiente de regulación, impiden a esta Junta informar favorablemente a la inmediata implantación de la indicada propuesta "22.

Por último, conviene poner de relieve las enormes expectativas que se generaron en el último tercio de 2004 en torno a la implantación del voto electrónico. El presidente del Gobierno, José Luis Rodríguez Zapatero, anunció en pleno mes de agosto que el Gobierno estudiaba la posibilidad de introducir el voto electrónico con ocasión del referéndum de la Constitución Europea de febrero de 2005 . Esta previsión fue muy bien recibida por todas las distintas fuerzas políticas, pero la inmediatez de la cita electoral y la inevitable exigencia de reformar con carácter previo la Ley del Referéndum y la Ley Electoral, la frenaron en seco, sin que el empuje de ese momento volviera, sin embargo, a retomarse con posterioridad ${ }^{23}$.

22 Se trata del Acuerdo de 22 de marzo de 2007, emitido por la Junta Electoral Central en respuesta a la solicitud de la Comunidad Autónoma de Madrid de que informara sobre la viabilidad de una propuesta de voto mediante urna electrónica en las elecciones a la Asamblea de Madrid de 27 de mayo de 2007.

23 Esta iniciativa giraba, no obstante, más en torno a voto electrónico a distancia, que presencial. Se llevaría a cabo, en palabras del Presidente "conforme a la propuesta que ensayó el Consistorio de Jun el pasado 14 de marzo, con motivo de las autonómicas andaluzas, de voto electrónico remoto a través de Internet y telefonía móvilw. 


\section{RECOMENDACIONES BÁSICAS SOBRE SU IMPLANTACIÓN}

De todas formas, en el terreno del voto electrónico todavía queda mucho trecho por recorrer pues son muchos los problemas técnicos y organizativos que hay que superar, a fin de asegurar que sus ventajas sean rentables ${ }^{24}$. Contamos, no obstante, con un valioso bagaje teórico y práctico e incluso con orientaciones muy consensuadas dictadas por instituciones públicas. Es el caso de las Recomendaciones del Comité de Ministros del Consejo de Europa de septiembre de $2004^{25}$ o los Estándares para los sistemas de voto electrónico aprobados por la Comisión Electoral Federal de los Estados Unidos de América de abril de $2002^{26}$.

No hay que olvidar, por otro lado, que conseguir que la emisión del voto se configure en torno a un procedimiento electrónico requiere lograr previamente la confianza de los ciudadanos en el mismo. Los electores no deben albergar dudas sobre la seguridad de las llamadas "urnas electrónicas", es decir, deben tener confianza en que nadie pueda interferir el proceso de votación con la intención fraudulenta de eliminar, añadir o modificar votos.

Sería preciso, también, integrar esta modalidad de expresión del voto de forma armónica en el conjunto del sistema de votación; en concreto, habría que hacer compatible su introducción en uno o varios procedimientos de votación con el mantenimiento del voto en papel en otros. Así, por ejemplo, si se implantara el voto electrónico únicamente en el voto directo en los colegios electorales, y no en el voto a distancia, no tendría mucho sentido que las Mesas Electorales siguieran utilizando las urnas tradicionales para introducir sin más los sufragios emitidos a distancia, pues lo lógico sería que estos sufragios fueran susceptibles de lectura electrónica, sin necesidad de abrir los sobres, y que la Mesa Electoral los pasara directamente por la máquina de votación, a fin de unificar el modo de escrutinio.

A lo ya dicho sobre la introducción del voto electrónico, tan solo queremos añadir varias reflexiones prácticas de carácter general en orden a su adecuada implantación en el futuro. Son tres:

- El sistema de voto electrónico que se implante debe ser lo más parecido posible al sistema de votación actual, pues sólo así será aceptable para el ciudadano común. Debería girar en torno a cuatro elementos:

24 Hay opiniones muy críticas con el voto electrónico. Vid., por ejemplo, el informe de junio de 2007 del Open Rights Group, tras el ensayo de voto electrónico en las elecciones locales británicas de mayo de 2007 (accesible en www.openrightsgroup.org). Vid. también. el informe Sistemas electrónicos de votación: fortalezas y debilidades, elaborado por el Grupo de Trabajo Nuevas Tecnologías y Procesos Electorales, del Ministerio del Interior de Argentina (accesible en la dirección electrónica del Ministerio: http://www.mininterior.gv.ar).

25 Recommendation Rec (2004) 11 of the Committee of Ministers to member states on legal, operational and technical standards for e-voting (adopted by the Committee of Ministers on 30 September 2004 at the 898th meeting of the Ministers' Deputies).

26 Estos estándares fueron aprobados el 30 de abril de 2002, después de tres años de discusiones y ensayos. 
tarjeta de votación con banda magnética; cabina electoral; ordenador situado dentro de la cabina y que permita al elector votar y registrar el voto en la tarjeta; y urna electrónica que registre los votos de forma automática conforme se van introduciendo las tarjetas ${ }^{27}$.

- Debe salvaguardarse en todo momento el secreto del voto y las demás condiciones básicas del sufragio reconocidas en la Constitución. En este sentido es fundamental que el recuento de los sufragios no sea accesible hasta la conclusión de la votación, ni tampoco la secuencia seguida por los electores en la expresión del voto.

- Hay que planificar cuidadosamente la implantación del voto electrónico, pues si no, se puede generar en los ciudadanos el rechazo al mismo y la desconfianza hacia los resultados electorales. En primer lugar, hay que seguir con la política de ensayos en algunas Mesas Electorales ${ }^{28}$; en segundo término habrá que hacer ensayos en circunscripciones enteras o incluso en todo el territorio afectado por las elecciones a celebrar; más tarde habrá que entrar en una fase en que fuera obligatorio realizar el voto en los dos sistemas, comenzando también aquí poco a poco; finalmente, habrá que ir progresivamente implantando el voto electrónico en exclusiva.

Esta última consideración sobre la introducción pausada del voto electrónico es, a nuestro juicio, la más delicada, complicada y arriesgada de todas. Requiere, por ello, de una elevada dosis de "finezza" y "sensibilità" por parte de nuestros políticos. Lo ideal, como punto de partida, sería comenzar por dar los pasos para su implantación en unas elecciones autonómicas determinadas, y ello por la capacidad normativa que tienen las Comunidades Autónomas para implantar esta modalidad de votación ${ }^{29}$, la limitación territorial que entrañan las elecciones autonómicas, su organización y desarrollo autónomo y la posibilidad de eliminar o reducir las distorsiones que puedan producir diver-

27 La secuencia sería más o menos ésta: el elector debería recibir del Presidente de la Mesa Electoral una tarjeta, introducirse en la cabina, hacer uso del ordenador que hay en ella para votar y registrar el voto en la tarjeta y, finalmente, entregarle la tarjeta al Presidente para su introducción en la urna electrónica, momento en que el voto queda registrado internamente.

28 Para afianzar la confianza de la población en el nuevo sistema de votación, sería conveniente que los primeros ensayos de voto electrónico tuvieran carácter de "mera prueba", sin validez jurídica alguna. No obstante, en cuanto se demostrase la fiabilidad del método utilizado, los ensayos deberían tener eficacia jurídica.

29 Vid. Juan C. GaVARA DE CARA, La homogeneidad de los regímenes electorales autonómicos, Centro de Estudios Políticos y Constitucionales y Fundación Manuel Jiménez Abad, Madrid, 2007, págs. 285 y ss.; Pablo SANTOLAYA MACHETTI, "La delimitación de competencias entre el Estado y las Comunidades Autónomas en materia electoral", Revista de Derecho Político, núm. 24, 1987, págs. 37 y 42 y ss.; Miguel Á. PRESNO LINARES, "El derecho de sufragio en los regímenes electorales autonómicos", en Cuadernos de Derecho Público, núms. 22-23 (El régimen electoral de las Comunidades Autónomas), 2004, pág. 195; y Luis A. GálvEZ MuÑoz, "Artículo 24. Las elecciones a la Asamblea Regional", en Mariano García Canales y Ángel Garrorena Morales (coords.), Comentarios al Estatuto de Autonomía de la Región de Murcia, co-edición Gobierno Regional, Asamblea Regional, Consejo Jurídico de la Región de Murcia y CajaMurcia, Murcia, 2005, págs. 1010-1013. 
sos elementos implicados en el desarrollo de las elecciones, como, por ejemplo, el voto a distancia de diversos colectivos desde diferentes lugares. Después habría que seguir actuando en elecciones que se desarrollen en todo el territorio nacional (generales, europeas o locales).

El tema es, sin duda, apasionante. Dejamos aquí, sin embargo, este breve estudio sobre el voto electrónico, pues el mismo constituye únicamente, hoy por hoy, una mera previsión de futuro. Tiempo habrá de volver sobre esta cuestión cuando el legislador defina una nueva etapa de los instrumentos de votación en España.

TITLE: About in-person e-vote: state of the art and recommendations for applying.

ABSTRACT: This study deals with the recent worldwide e-vote progress, its effects on suffrage right and suffrage process, its testing stage in Spain for several years and the progressive and unbrakeable technological development in this country. The paper also studies the regulations for material resources of vote, the benefits of in-person e-vote applying and its alternatives, this kind of vote's current legislation in Spain, the doctrine of Nacional Electoral Commision about suggested practice and, finally, the better way of e-vote applying. In one word, it aims to analyse the state of this art and make some suggestions about it.

RESUMEN: Este artículo aborda la extensión del voto electrónico, sus efectos en el derecho de sufragio y en el proceso electoral.

KeY WORDS: Key words. Political participation. Suffrage Law. Elections. Suffrage right. Voting. E-vote. E-democracy

Palabras clave: Participación politica. Derecho electoral. Elecciones. Derecho de sufragio. Votación. Voto electrónico. Democracia electrónica. 